\title{
Cool generation
}

Written by: Rory Clarke, OECD Observer

Last update: 5 December 2018

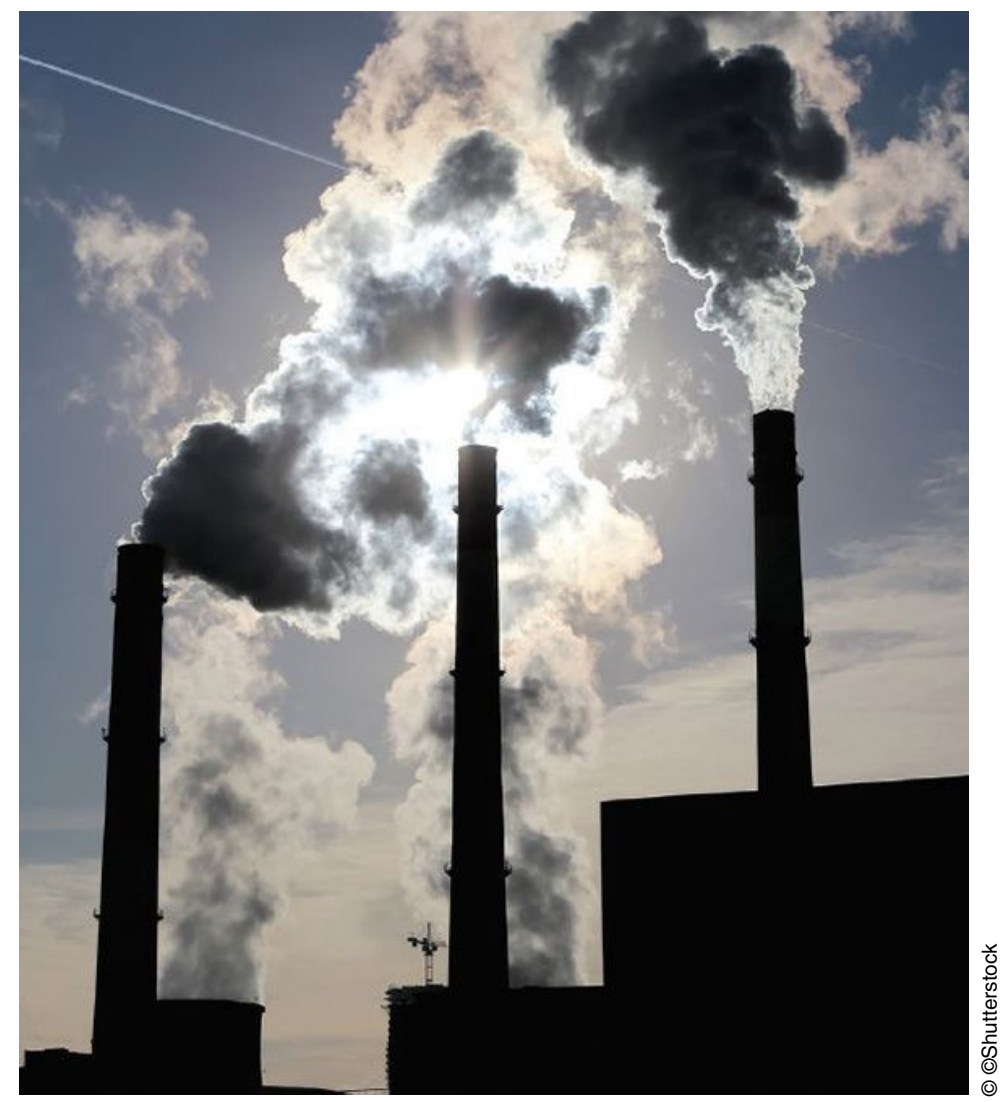

Cool generation

Climate change appears to be gathering pace, with the four years since 2015 being the hottest on record. Of course, 2015 was also the year the Paris Climate Agreement was signed by 195 countries, with the goal of holding the rise in the global average temperature to well within a maximum of $2^{\circ} \mathrm{C}$ above preindustrial levels over the long term. But that goal is in peril, which means efforts to reduce the greenhouse gas emissions must be stepped up.

One area for action is electricity generation, which accounts for some $40 \%$ of emissions from the energy sector, itself accounting for some $68 \%$ of global greenhouse gas emissions. The trouble is, some two-thirds of electricity comes 
from fossil fuel sources and, according to a new OECD working paper, electricity generation infrastructure under construction and planned in the next five years is simply not in line with a low-carbon scenario. True, renewable sources are expanding, but so is coal-fired electricity. Governments can and must do more to change this.

Globally, there are approximately 6,300 GW (gigawatt) of power capacity in operation, 1,200 GW currently under construction (to become operational in the next five years), with three countries-China, India and the United Statesaccounting for $72 \%$ of this. The numbers show that renewable energy technology is expanding rapidly: it represented only $34 \%$ of the installed capacity in 2017 yet accounts for $62 \%$ of the plants under construction (mostly from wind and solar power, with China being a major driver of this growth). In contrast, the development of new coal power plants is slowing: currently representing $31 \%$ of total installed generation capacity, coal power represents $23 \%$ of electricity capacity under construction.

Cool generation

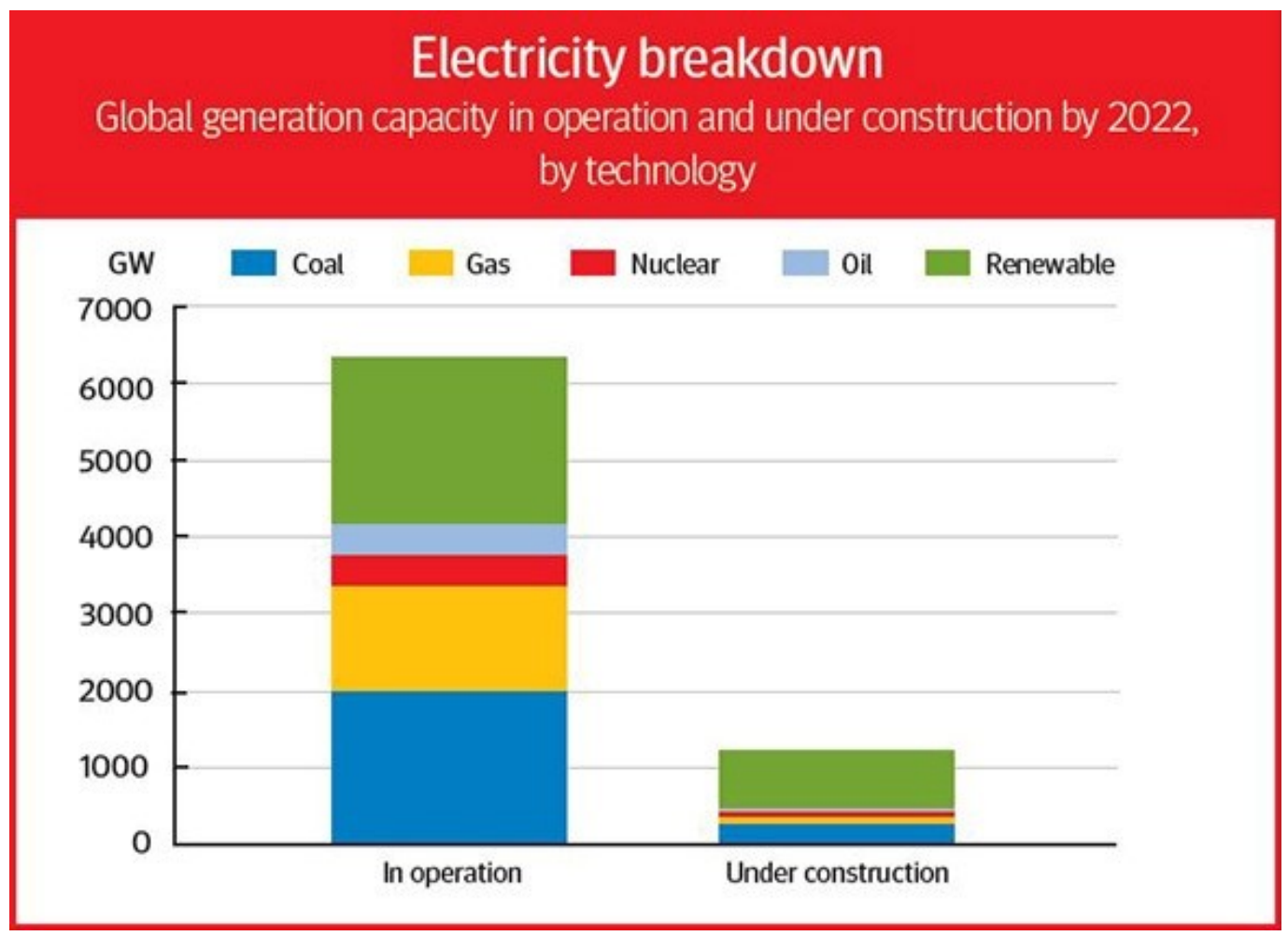

While these results provide encouraging signs that the energy sector is being decarbonised, data suggest that coal will still be the main source of electricity output by 2022. To be in line with 2020-30 energy scenarios that provide pathways for reaching the Paris Agreement goal, global coal capacity should be decreased by $2 \%$ per year in the 10 years from 2020 , rather than rise by $3 \%$ per year as it has done in the previous 10 . 
Meanwhile, renewable energy deployment, though going in the right direction, must be accelerated. Solar power, for instance, is deployed widely, but still accounts for only $1 \%$ of electricity generation, the authors point out.

A number of changes need to take place in the electricity sector to meet the Paris Climate Agreement's goals to combat global warming. Coal needs to be phased out rapidly, particularly in China, India and the US, by halting new construction and retiring existing ones; renewable energy technology needs to be more widely deployed; and investment in demand management needs ramping up. Government policy is key for encouraging these changes. But more than this, governments can take action as investors, not least by getting state-owned enterprises, which account for over half of electricity capacity, installed and under construction, to redirect electricity-related activities towards more sustainable sources of electricity.

In short, as this fact-packed working paper shows, decarbonising electricity will be the shock treatment needed for tackling climate change and making our planet cool again.

COOECD Observer No 316, Q4 2018

\section{References}

Mirabile, Mariana and Jennifer Calder (2018), "Clean power for a cool planet: Electricity infrastructure plans and the Paris Agreement", OECD Environment Working Papers, No 140, OECD Publishing, Paris. Available at http://dx.doi.org/ http://dx.doi.org/10.1787/2dc84376-en

For more on the 2015 Paris Agreement, see https://unfccc.int/ 